\title{
Sefer Shimmush Tehillim - Buch vom magischen Gebrauch der Psalmen
}

\author{
Edition, Übersetzung und Kommentar \\ Hrsg. v. Bill Rebiger
}

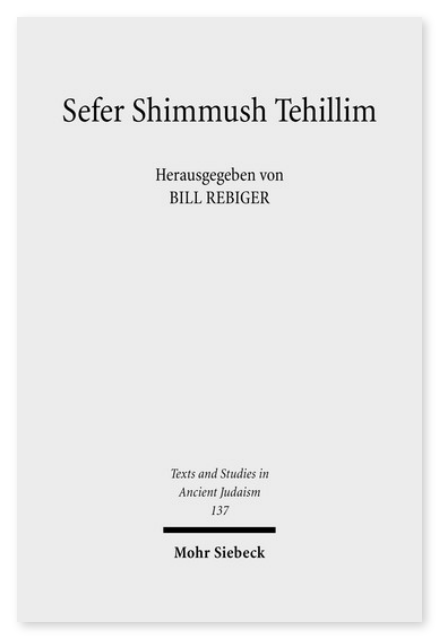

2010. IX, 359 Seiten $(+117 *)$.

TSAJ 137

ISBN 978-3-16-151470-8

DOI 10.1628/978-3-16-151470-8

eBook PDF 139,00€

ISBN 978-3-16-149774-2

Leinen $139,00 €$
Der Sefer Shimmush Tehillim (das »Buch vom magischen Gebrauch der Psalmen«) ist ein im Judentum teilweise bis heute populäres Handbuch, in dem den biblischen Psalmen magische Verwendungen zugeordnet werden. Die Anfänge seiner Redaktion reichen bis in die Spätantike und in den ägyptisch-palästinischen Raum zurück. Die ältesten erhaltenen Textzeugen stammen aus der Kairoer Geniza, sind in einer hebräisch-aramäischen Mischsprache verfaßt und wurden in einer repräsentativen Auswahl in Magische Texte aus der Kairoer Geniza, Bd. 3, hrsg. von Peter Schäfer und Shaul Shaked, Tübingen 1999 [TSAJ 72], erstmals ediert. Das Ende der hier umfassend dokumentierten, komplexen Redaktionsgeschichte dieses Manuals wird einerseits durch den Erstdruck Sabbioneta 1551, der zum textus receptus wurde, und andererseits durch die sefardische Rezension, die nur handschriftlich bezeugt ist, bezeichnet. In der vorliegenden Veröffentlichung ediert Bill Rebiger mittelalterliche und frühneuzeitliche Handschriften sowie die editio princeps synoptisch. In einer zweispaltigen Synopse übersetzt er den Erstdruck und die sefardische Rezension ins Deutsche und kommentiert in Anmerkungen Probleme der Übersetzung. In einem separaten Einzelkommentar widmet er sich ausführlich den Beziehungen zwischen dem Text eines Psalms und seiner jeweiligen magischen Verwendung sowie zwischen den Rezensionen, den text- und traditionsgeschichtlichen Entwicklungen, den Paralleltexten aus der magischen Literatur und der ritualtheoretischen Analyse der Handlungsanweisungen. Eine allgemeine und forschungsgeschichtliche Einleitung und verschiedene Indices komplettieren dieses Buch.

Bill Rebiger ist wiss. Mitarbeiter an der Philipps-Universität Marburg und hat regelmäßige Lehraufträge am Institut für Judaistik an der FU Berlin.

\section{Jetzt bestellen:}

https://mohrsiebeck.com/buch/sefer-shimmush-tehillim-buch-vom-magischen-gebrauch-der-psalmen-9783161514708? no_cache=1

order@mohrsiebeck.com

Telefon: +49 (0)7071-923-17

Telefax: +49 (0)7071-51104 